\title{
Role of extracellular vesicles in the progression, diagnosis and treatment of thyroid cancer (Review)
}

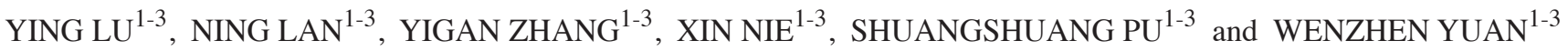 \\ ${ }^{1}$ The First School of Clinical Medicine, Lanzhou University; ${ }^{2}$ Department of Oncology, \\ The First Hospital of Lanzhou University; ${ }^{3}$ Key Laboratory for Resources Utilization Technology of \\ Unconventional Water of Gansu Province, Gansu Membrane Science and Technology Research Institute, \\ Gansu, Lanzhou 730000, P.R. China
}

Received April 28, 2020; Accepted August 4, 2020

DOI: $10.3892 /$ ijo.2020.5111

\begin{abstract}
Extracellular vesicles (EVs) enclose a myriad of proteins and nucleic acids that are released in the extracellular milieu of cells through EVs. These secreted molecules serve as signaling factors that can alter the biological characteristics of tumor cells. Several studies have suggested that EVs are associated with tumor proliferation, metastasis and microenvironmental regulation in thyroid carcinoma (TC). The biomolecules in EVs can serve as differential diagnostic biomarkers for TC. Moreover, EVs derived from natural killer (NK) cells can be developed as potential immunotherapeutic agents, since they can actively target and kill tumor cells in TC. Recent years have witnessed a steep rise in the number of TC cases, and thus, accurate diagnosis and novel TC treatment strategies are being actively explored. The present review discusses the recent research investigations on EVs as far as the biological, clinical diagnosis and treatment of primary TC tumors are concerned. In addition, the new opportunities and challenges encountered in the practical applications of EVs in thyroid carcinoma are outlined.
\end{abstract}

\section{Contents}

1. Introduction

2. Characteristics of EVs

3. Role of EVs in TC progression

4. Role of EVs in TC diagnosis

5. Potential applications of EVs in the treatment of TC

6. Conclusions and future perspectives

Correspondence to: Dr Wenzhen Yuan, Department of Oncology, The First Hospital of Lanzhou University, 199 Donggang West Road, Gansu, Lanzhou 730000, P.R. China

E-mail: yuanwzh@lzu.edu.cn

Key words: thyroid carcinoma, extracellular vesicles, tumor microenvironment, biomarkers, targeted therapy, immunotherapy

\section{Introduction}

Thyroid carcinoma (TC) is the most prevalent malignant tumor of the endocrine system, as well as the head and neck. It is the most common type of tumor among adolescents and youths, and its incidence growth rate is highest among females (1-3). Statistically, approximately $70 \%$ of thyroid nodules are diagnosed as benign prior to the surgical procedure, $5-10 \%$ as malignant (4), and approximately 10-30\% remain uncategorized (5). Among these uncategorized nodules, only $20-25 \%$ are eventually identified as TC following surgery, accounting for approximately $75-80 \%$ of unnecessary thyroidectomies in patients $(6,7)$. Thus, the detection of specific diagnostic markers for goiter that do not implicate fine needle aspiration may mitigate unnecessary thyroidectomies (8). Additionally, apart from papillary TC (PTC) and follicular TC (FTC), approximately $3 \%$ of TC cases are categorized as myeloid TC (MTC) and anaplastic TC (ATC). However, MTC and ATC are poorly differentiated, which hamper their treatment. Thus, an in-depth analysis of MTC and ATC may improve the overall level of treatment in TC (9).

Extracellular vesicles (EVs) are small membrane vesicles with lipid bilayer membrane structure (10). EVs were isolated from serum, saliva, urine, semen, breast milk, amniotic fluid, ascites, cerebrospinal fluid, bile and a variety of body fluids (11). Liquid biopsy plays a crucial role in the primary screening of cancer, the identification of malignant nodules, the prediction of local TC metastasis, the assessment of prognosis and the treatment response in cancer. In addition, liquid biopsy is comparatively less invasive than traditional diagnostic tests. Moreover, EVs may also regulate a myriad of intracellular life processes by exerting autocrine and paracrine functions (12). EVs play vital physiological roles in immune regulation, tumor growth infiltration, coagulation, tissue homeostasis and neurodegenerative diseases (13). Additionally, EVs are considered promising natural drug carriers due to their relatively stable membrane structure and better biocompatibility $(14,15)$. The contents and transportation routes of EVs can be engineered, rendering EVs an efficient tool for targeted tumor therapy (16) and for counteracting drug resistance (17). The present review systematically expounds the recent research investigations on EVs in TC and discusses the new opportunities and challenges as regards the application of EVs in thyroid tumors. 


\section{Characteristics of EVs}

Generally, EVs are categorized as exosomes $(30-200 \mathrm{~nm}$ in diameter), microvesicles (200-1,000 $\mathrm{nm}$ in diameter) and apoptotic bodies $(50-5,000 \mathrm{~nm}$ in diameter) $(18,19)$. Early endosomes are formed by non-clathrin or clathrin-mediated endocytic processes. Early endosomes wrap part of the cytosol by invaginating inward to form intraluminal vesicles (ILVs). At this time, early endosomes mature to form multivesicular bodies (MVBs). Exosomes are formed when ILVs stored in MVBs are released into the extracellular space, post-MVB and cell membrane fusion. Unlike exosomes, microvesicles are released directly in the extracellular space via exocytosis (20). Moreover, when the cell initiates the apoptotic program, the fusion of MVBs and lysosomes forms apoptotic bodies. EVs mediate intercellular communication by secreting proteins (21) and nucleic acids (22). Intercellular communication is crucial in multicellular organisms, and it occurs either by the uptake or by the secretion of the signaling factors. All eukaryotic (such as amoebae, Caenorhabditis elegans and mammalian parasites) and prokaryotic cells release vesicles into the extracellular environment (23) (Fig. 1). It should be noted that the fusion of MVBs with lysosomes often results in the degradation of MVBs and the recycling of their raw materials. Thus, apoptotic bodies are not secreted in the extracellular environment, so they do not participate in intercellular communication. Exosomes and microvesicles have become major concerns as regards cancer progression (12). Microvesicles are usually larger than exosomes, and their composition is identical to that of parent cells (24). Exosomes carrying specific signaling substances can participate in a variety of life processes through intercellular communication (Table I). However, the inability of the commonly used commercial exosome purification kits and protocols to segregate the microvesicles and exosomes needs to be emphasized (10). Furthermore, published articles have not fully succeeded in specifying the subtypes of their vesicular samples. Therefore, as per the recommendation of the International EVs Society, microvesicles and exosomes should be collectively addressed as EVs. However, the term subtype should be used with caution in the absence of reliable subcellular origin markers (25).

Initially, vesicles $40-1,000 \mathrm{~nm}$ in diameter released by different types of cells were termed as exosomes (26). Subsequently, Harding et al reported that MVBs and plasma membrane fusion initiates the release of exosomes in extracellular space. Their study demonstrated that MVBs were involved in the process of exosomal release (27). Based on this finding, exosomes were considered to be vesicles $40-100 \mathrm{~nm}$ in diameter released by the fusion of the MVBs with the plasma membrane (28). Previous studies confined the cellular functions of vesicles, primarily to the waste secretion, and thus EVs failed to attract ample attention. Subsequently, EVs re-entered the researcher's vision as an essential intercellular communication medium. In the 1990s, Raposo et al and Zitvogel et al found that the EVs released by B lymphocytes and dendritic cells had the antigen-presenting ability, which stimulated the T-cell-dependent anti-tumor effects $(29,30)$. In 2007, Valadi et al, for the first time, reported the exosome-mediated intercellular exchange of genetic materials. Exosomes from tumorigenic cells promoted the tumor progression and metastasis, and exosomes secreted by adjacent normal cells had tumor-killing capacity (31). These findings shifted the focus of researchers to EVs and encouraged a plethora of studies, exploring the potential of clinical translation of EVs. EVs secreted by Gram-negative bacteria can be utilized as vectors to deliver lipopolysaccharide (LPS) into the host cytoplasm, triggering an intracellular caspase-11-dependent immune response (32). In addition, EVs carrying suicide mRNA and protein following genetic engineering can play a role in the treatment of schwannoma (33). These studies have paved the way for the advancement of clinical application of EVs. Recently, a series of discoveries have tapped the role of EVs in cancer and the immune system. Several new studies on TC are currently focusing on the development, diagnosis, and treatment of TC. In view of this, it is necessary to summarize the role of EVs in TC.

\section{Role of EVs in TC progression}

EVs persist in the body fluid and tumor microenvironment of cancer patients. Within $2 \mathrm{~h}$ of secretion by tumor cells, EVs directly interact with other tumor cells and become engulfed within $24 \mathrm{~h}$ by these cells (34). These internalized signaling molecules regulate the pathophysiological state of the recipient cells. Therefore, functional characterization of the TC-derived exosomal content can provide the clues for unraveling the underlying mechanism for the TC occurrence and development (Fig. 2).

EVs affect the growth of TC. The content of tumor-derived EVs is also involved in the regulation of TC proliferation. The miR-146b and miR-222 levels in the TPC-1 derived exosomes (PTC cell line) were higher than those of NTHY cells (normal thyroid cells). The T-EXO (TPC-1 derived exosomes) inhibited the proliferation of TPC-1 and NTHY cells (35). However, some studies have demonstrated that these two miRNAs increased the proliferation of normal thyroid and TC cells $(36,37)$. The inconsistency in these studies may be as the latter did not involve EV-mediated miRNA transfer; in addition, miRNAs may regulate receptor cells through different targets in different processes. Moreover, circFNDC3B and circRASSF2 were significantly upregulated in serum purified EVs (SPEs) derived from patients with PTC, and their downregulation inhibited the proliferation and promoted the apoptosis of PTC cells. Further research studies found that both of these circRNAs act as a sponge of miR-1178 and regulate the miR-1178-TLR4 axis in promoting the PTC progression $(38,39)$.

EVs promote the invasion and metastasis of TC. The contents of tumor-derived EVs regulate the invasion and metastasis of recipient cells during the process of intercellular exchange (40). A previous study reported that the typical proteins associated with the integrin-mediated cell adhesion pathway, i.e., ITGA2, ITGA2B, ITGAV, ITGB1, ITGB2 and ITGB3, along with the proteins located in the upstream of the integrin pathway, i.e., TLN1, ITGB2, CAPNS1 and SRC, were overexpressed in SPEs of patients with PTCs with lymph node metastasis (LNM) (41). As per the previous classic hypothesis on metastasis, tumor cells secreted EVs prior to the onset of 


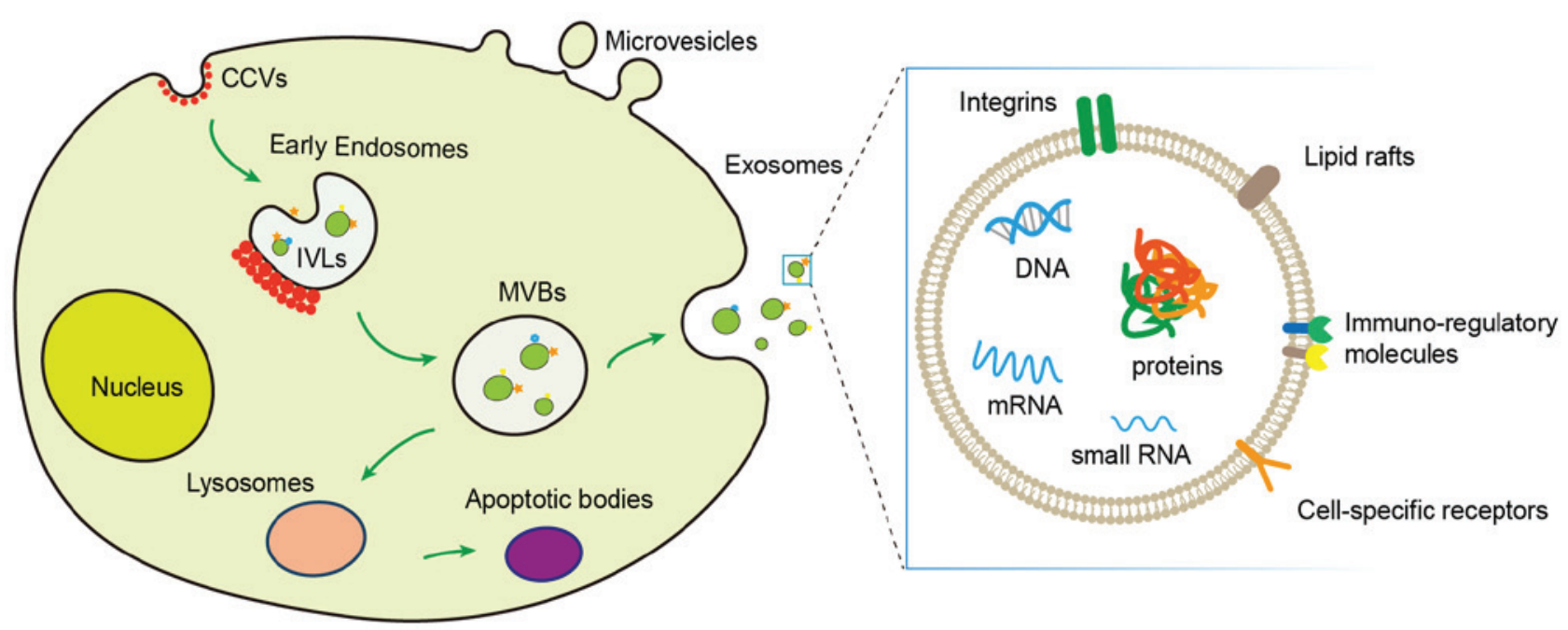

Figure 1. Biogenesis and structural composition of EVs. EVs include exosomes, microvesicles and apoptotic bodies. After the fusion of MVBs with the cell membrane, the IVLs in the MVBs are released outside the cell and become exosomes. The microvesicles bud directly from the cell surface, and apoptotic bodies are formed by the fusion of MVBs and lysosomes. EVs contain proteins, lipids, and nucleic acids (DNA, mRNA and small RNA), which are crucial signaling molecules for intercellular communication functions. Red dots represent CCVs. Triangles, rectangles and pentagons represent membrane-associated and transmembrane proteins on the vesicles. Arrows indicate the transport direction of proteins and lipids between organelles, MVBs and plasma membrane during exosome secretion. EVs, extracellular vesicles; MVBs, multivesicular bodies; IVLs, intraluminal vesicles; CCVs, clathrin-coated vesicles.

metastasis, and these EVs reached the pre-metastatic site via the circulatory system. The components in EVs can affect the recipient cell environment and form a microenvironment suitable for tumor cell growth, the 'pre-metastatic niche' (42-44). Therefore, the abnormal expression of integrin in SPEs of patients with PTC with LNM may be involved in the formation of a pre-metastatic niche. SRC inhibitors have also been shown to inhibit the proliferation and invasion of PTC cells (45). Furthermore, ACTB, ALDOA, MAPK1 (ERK2), RAC1, ANXA1 and HSP27 have been shown to also be overexpressed in SPEs from patients with PTC with LNM, which promoted the invasion and metastasis of TC. Among these, RAC1 gene knockdown was shown to alleviate the migration and invasion of TPCB1 and HTH83TC cells (46).

The underlying mechanism for the EV-mediated regulation of TC metastasis is not limited to proteins only, but it includes a number of non-coding RNAs, such as lncRNAs, cricRNAs and miRNAs. According to a previous study, TC stem cell (TCSC)-derived EVs induce epithelial-mesenchymal transition (EMT) in normal thyroid cells by transferring lnc-ROR (47). EMT leads to a loss of polarity, close intercellular connection and adhesion (loss of e-cadherin, and so on) in epithelial cells through a series of reactions and facilitates invasion and migration in these cells. lnc-ROR overexpression in TCSCs significantly enhances the proliferation and invasion of target cells. This indicates that the intervention of stem cells, stem cell-derived EVs or lncRNAs has the potential to inhibit tumor metastasis.

A recent study reported the expression levels of circRNAs in SPEs of PTC and benign goiter by using high-throughput sequencing. In that study, SPEs from patients with PTC exhibited 3 upregulated (hsacirc-u007293, hsacirc-u031752 and hsacirc-u020135) and 19 downregulated circRNAs. It was also found that these differentially expressed circRNAs regulated 16 signaling pathways, among which the PI3K-Akt and AMPK signaling pathways participated in the invasion and metastasis of TC (48). Apart from circRNAs, some studies have reported that miRNAs in EVs derived from patients with PTC also play a role in metastasis. The augmented migration and invasion of PTC cells have been observed in patients with PTC with significantly escalated miR-423-5p levels in SPEs (49). Also, increased levels of miR-146b-5p and miR-222-3p were observed in SPEs from PTC patients with LNM as compared to PTC patients without LNM. Wound healing experiments and Transwell assays have proven that the upregulation of miR-146b-5p and miR-222-3p in PTC cell lines (K1 cells and BCPAP cells) significantly enhances the invasion and migration of PTC cells and their downregulation results in opposite effects (50).

EVs affect the microenvironment of TC. The tumor microenvironment promotes the onset of the tumor and sustains its development, in a similar manner to that of soil with seeds. Immune cells, nascent tumor cells, tumor extracellular matrix and tumor blood vessels in the tumor microenvironment co-evolve with tumor cells (51). Multiple mechanisms have been proposed to explain the TC microenvironment, with EVs being an integral part of these.

Effects of TC-derived EVs on fibroblasts. Recently, a new mode of EVs involved in TC metastasis has been proposed, $\mathrm{TC}$ and fibroblast $(\mathrm{Fb})$ cell crosstalk. Herein, it was previously demonstrated that $\mathrm{Fb}$ or $\mathrm{Fb}$ and $\mathrm{TC}$ cell co-culture-derived conditioned medium (CM) induces the migratory phenotype of TC cells, such as MMP2 activation and the formation of filopodia and lamellipodia in TC. Moreover, EVs extracted from the CM of Fb-TC exhibited CD147 overexpression and MMP2 secretion. The CD147 interaction with interstitial tumor cells promoted MMP2 secretion and activation. The $\mathrm{Fb}$ and TC cell co-cultured CM and EVs promoted metastasis and invasive phenotypic alterations in $\mathrm{TC}$ and $\mathrm{Fb}$ cells (52). The TC and Fb crosstalk promoted TC cells and Fb EMT and tumor progression in general. 
Table I. General characterizations of the extracellular vesicles.

\begin{tabular}{|c|c|c|c|c|}
\hline & Markers & Size $(\mathrm{nm})$ & Origin & $\begin{array}{l}\text { Intercellular } \\
\text { communication }\end{array}$ \\
\hline Exosomes & $\begin{array}{l}\text { Proteins: Tetraspanins (CD9, CD82, CD81, CD63), } \\
\text { cytoplasmic proteins (Rab, annexins), co-stimulatory } \\
\text { molecules (CD86), adhesion molecules (CD54 } \\
\text { and CD11b), membrane proteins (CD55, CD59), } \\
\text { heat shock proteins (Hsp70, Hsp90). } \\
\text { Immunomodulators: MHC-I; MHC-I. } \\
\text { Nucleic acids: DNAs, miRNAs, mRNAs, } \\
\text { non-coding RNAs. } \\
\text { Lipids }\end{array}$ & $30-200$ & $\begin{array}{l}\text { Fusion of MVBs } \\
\text { with plasma } \\
\text { membrane }\end{array}$ & Yes \\
\hline Microvesicles & $\begin{array}{l}\text { Selectins; integrins; tissues factor and cell-specific } \\
\text { markers }\end{array}$ & $200-1,000$ & $\begin{array}{l}\text { Exocytosis of } \\
\text { cell plasma } \\
\text { membrane }\end{array}$ & Yes \\
\hline Apoptotic bodies & Histones; organelles & $50-5,000$ & $\begin{array}{l}\text { Fusion of MVBs } \\
\text { with lysosomes }\end{array}$ & No \\
\hline
\end{tabular}

MVBs, multivesicular bodies.

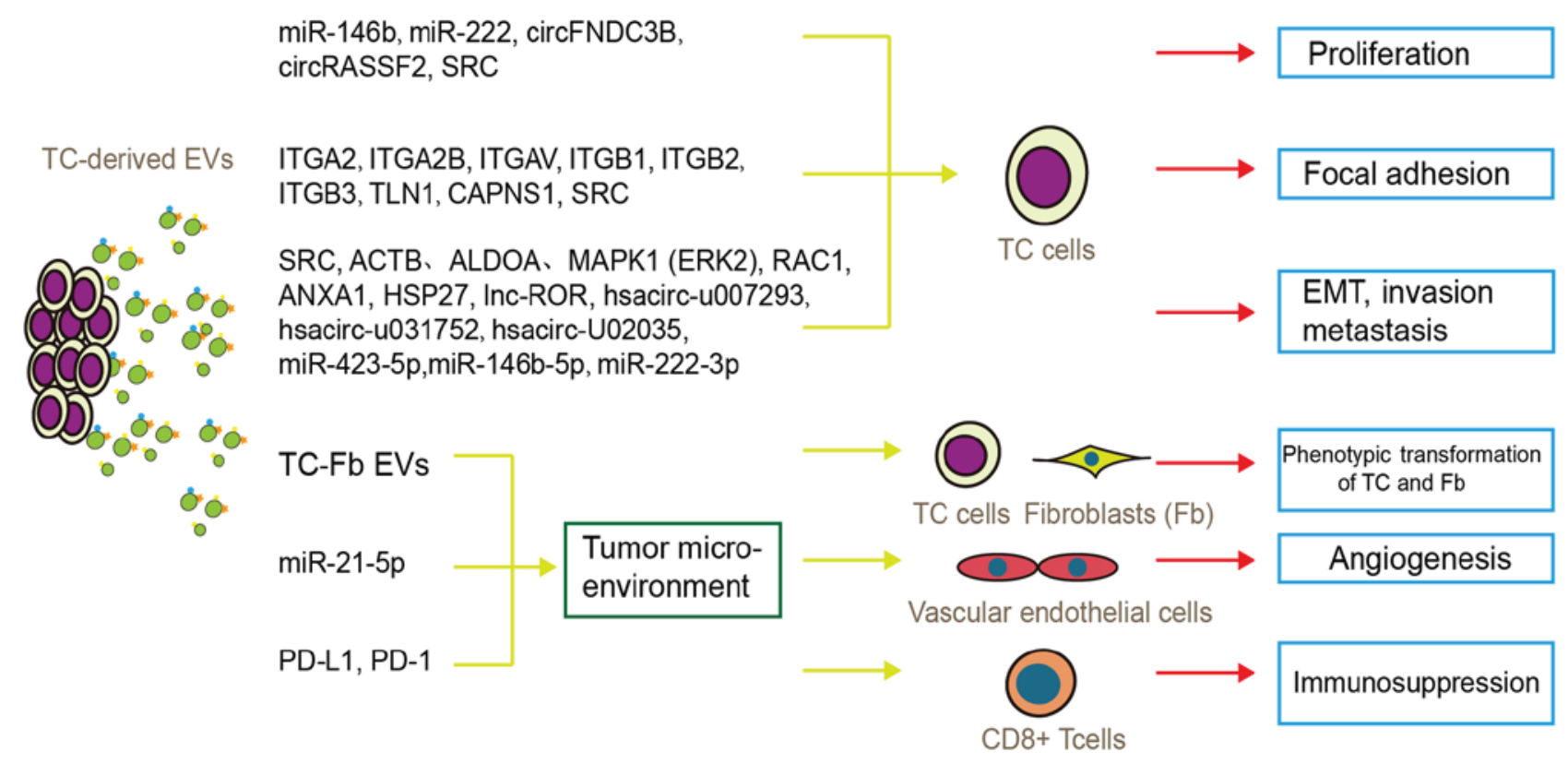

Figure 2. Function of tumor-derived EVs in TC progression and tumor microenvironment regulation. TC-derived EVs participate in tumor cell proliferation, invasion, metastasis, EMT, and microenvironmental regulation (phenotypic transformation of TC and Fbs, angiogenesis, and immunosuppression) via multiple proteins and RNAs. EVs, extracellular vesicles; EMT, epithelial-mesenchymal transition; Fb, fibroblast; TC, thyroid carcinoma.

Effects of TC-derived EVs on angiogenesis. It was previously reported that the miR-21-5p expression level in PTC cell (BCPAP and KTC-1 cell lines)-derived EVs under hypoxic conditions was significantly higher than that of normal thyroid follicular cell line (Nthy-ori-3-1) and normoxic PTC cells. In addition, the miR-21-5p expression level in SPEs of patients with PTC was higher than that of healthy individuals. PTC cells derived exosomes under hypoxic conditions promoted the vascular endothelial cells formation, and conversely, miR-21-5p downregulation or normoxic conditions inhibited it. The angiogenic ability of SPEs from patients with PTC was also confirmed at the tissue level. It was found that miR-21-5p promoted this process by directly targeting and inhibiting TGFBI and COL4A1 (53).

Effects of TC-derived EVs on immune cells. The status of immune cells in the tumor microenvironment is also closely related to tumor progression. Immune cells, such as B cells, tumor-associated macrophages (TAM) and Tregs suppress cytotoxic $\mathrm{T}$ cells and $\mathrm{CD} 8^{+} \mathrm{T}$ cells via $\mathrm{EVs}$, and promote immune escape and drug resistance in tumor cells (54). Tumor 
cells also secrete EVs to mitigate the immune cell activation and cytokine secretion. A previous study reported that the PD-1 and PD-L1 levels were significantly higher in children with PTC than in healthy children. When EVs with high PD-L1 expression were co-incubated with $\mathrm{CD}^{+} \mathrm{T}$ cells, the PD-1 level remained unaffected, although the levels of inflammatory cytokines (CD69, IFN- $\gamma$ and TNF- $\alpha$ ) were significantly depleted. This suggests that PD-L1 can bind to PD-1 expressed on the surface of $\mathrm{CD} 8^{+} \mathrm{T}$ cells and interfere with the effector $\mathrm{T}$ cell activation (55).

\section{Role of EVs in TC diagnosis}

The diagnostic accuracy of tumors can be enhanced by employing liquid biopsy as an alternative and complementary diagnostic method in cases where the cytological diagnosis is uncertain. It can also reduce the rate of invasive puncture, easing the overtreatment of patients with benign nodules. EVs secreted into body fluids stably retain the vesicle's content and partial characteristics of secretory cells (56). The signaling biomolecules of EVs can be categorized as non-specific and specific. Non-specific biomolecules are primarily related to the common biological characteristics of EVs, such as vesicle formation, binding with receptor cells and so on. Therefore, these molecules are employed for the isolation and identification of EVs. However, the specific biomolecules precisely reflect the parent cell condition, such as carcinogenesis or metastasis (57). Thus, summarizing the TC-specific molecules in the EVs could assist the diagnosis and prognosis of TC along with the recurrence and metastasis prediction.

Previous studies have reported that miR-146b, miR-222 (35), miR-5189-3p (58), circFNDC3B (circ_0006156) (38), circRASSF2 (circ_0059354) (39), miR-31-5p, miR-21-5p (59), miR-346, miR-10a-5p, miR-34a-5p (60), hsacirc_007293, hsacirc_031752, hsacirc_020135 (48) and miR-4433a-5p (61), which were overexpressed in EVs, serve as diagnostic biomarkers for PTC and FTC, to identify TC and distinguish it from healthy or benign thyroid nodules (Table II) (62). In addition, miR-485-3p functions as a prognostic biomarker for TC. The overexpression of miR-485-3p in the SPEs from patients with PTC is associated with a tumor size $\geq 1 \mathrm{~cm}$, extrathyroid metastasis, lymph node metastasis and BRAF mutation. Thus, miR-485-3p can be used as a biomarker to distinguish high-risk from low-risk PTC (61). Concurrently, EV markers suggesting the LNM of TC have also been discovered. The overexpression of miR-146b-5p and miR-222-3p in SPEs indicates LNM in patients with PTC, and these biomarkers have demonstrated 81.1 and $83.4 \%$ area under the curve (AUC) values, respectively. Notably, the AUC values increased to $89.5 \%$ when expression levels of these two miRNAs were collectively analyzed (50). Previous studies have stated the diagnostic advantages of using multiple biomarkers. The combined analysis of miR-21-5p and miR-181a expression in SPEs can distinguish PTC and FTC with $100 \%$ sensitivity and $87 \%$ specificity (59). The combined analysis of miR-16-2-3p, miR-223-5p, miR-101-3p and miR-34c-5p expression in SPEs can differentiate PTC from benign goiter (BG) with 74\% AUCs, $100 \%$ sensitivity and $87 \%$ specificity (63), yielding higher values than those estimated using individual biomarkers.
In addition to non-coding RNAs, EV proteins can also serve as diagnostic biomarkers for TC. A previous study included patients with differentiated thyroid carcinoma (DTC) at different stages and analyzed the levels of serum thyroglobulin and urinary exosomal thyroglobulin (U-Ex-Tg). The outcomes indicated that the U-Ex-Tg levels were higher in TC patients with T3 stage or LNM than in those with T1 and T2 stages. Notably, increased serum thyroglobulin levels, post-surgery, were not detected in TC patients with a high risk of recurrence. However, the U-Ex-Tg levels were significantly elevated. This suggests that U-Ex-Tg can act as a more sensitive molecular marker for prognosis and the post-operative recurrence prediction of DTC (64). It was also found that HSP27, HSP60 and HSP90 in SPEs from patients with PTC were higher than those in peritumoral tissues (PT) and BG. These SPEs markers from preoperative PTC were higher than in PTC, post-surgery. Moreover, these markers were located in normal sites, such as the cytoplasm in BG samples, but closer to the plasma membrane in PTC tissues; thus, it is likely that EVs enclosed these markers, which later participated in the intercellular communication of TC (65). Moreover, the PD-L1 and PD-1 levels in SPEs from children with PTC were found to be significantly higher than in healthy children, and PD-L1 had an 81.4\% AUC value. Moreover, the PD-L1 level in SPEs prior to PTC surgery was higher than that post-surgery, and PD-L1 overexpression was associated with T staging (55).

\section{Potential applications of EVs in the treatment of TC}

$T C$-derived EVs can target tumor regions. Due to the low immunogenicity and toxicity, stable membrane structure, high biocompatibility and biological permeability of EVs $(15,66,67)$, several studies have explored the applicability of EVs in tumor therapy. The receptor present on the tumor-derived EVs binds to the ligand present on the tumor cells and mediates the fusion of tumor cells with the tumor-derived EVs (68). Previous studies have demonstrated that tumor-derived EVs were more easily internalized by tumor cells compared with EVs derived from epithelial cells (69). The specific expression of tetraspanins (a receptor protein) in EVs enables its preferential binding to specific ligands for the selection of receptor cells (70). Therefore, engineered EVs can target a specific tumor type and can function as a therapeutic agent. It can effectively mitigate the side-effects caused by other modes of cancer treatment. EVs with hepatocyte growth factor (HGF) siRNAs that are transported to gastric cancer (GC) cells have been shown to potentiate the therapeutic effect of tumor growth and angiogenesis inhibition (71). This provides a valuable reference for EVs in the treatment of TC. In the study conducted by Gangadaran et al, CAL62 (ATC cell line)-derived EVs labeled with Renilla luciferase (Rluc) were injected into tumor-bearing mice and the targeting accuracy of EVs for thyroid tumors was monitored (72). Rluc is an efficient monitoring tool due to its real-time monitoring and high sensitivity. This method prevented the inclusion of non-specific signal interference and EV damage caused by the lipophilic dyes, the high signal-to-noise ratio of bioluminescent imaging (BLI), and the low sensitivity of MRI. The authors of that study noted that the CAL62-cells derived EVs were explicitly 
Table II. Thyroid carcinoma biomarkers in extracellular vesicles (62).

\begin{tabular}{|c|c|c|c|c|c|c|}
\hline Biomarkers & $\begin{array}{l}\text { Expression } \\
\text { level in TC }\end{array}$ & $\begin{array}{l}\text { Research } \\
\text { objects }\end{array}$ & $\begin{array}{l}\text { Predictive } \\
\text { indicator }\end{array}$ & $\begin{array}{l}\text { Sample } \\
\text { sources }\end{array}$ & $\begin{array}{l}\text { Sensitivity, specificity } \\
\text { or AUC values }\end{array}$ & (Refs.) \\
\hline $\begin{array}{l}\text { miR-146b } \\
\text { miR-222 }\end{array}$ & Up & PTC vs. HC & $\begin{array}{l}\text { Differential } \\
\text { diagnosis }\end{array}$ & Cell lines & Not mentioned & $(35)$ \\
\hline $\operatorname{miR}-5189-3 p$ & Up & PTC vs. BG & $\begin{array}{l}\text { Differential } \\
\text { diagnosis }\end{array}$ & SPEs & $95.1 \%$ AUC & $(58)$ \\
\hline $\begin{array}{l}\text { circFNDC3B } \\
(\text { circ_0006156) }\end{array}$ & Up & PTC vs. HC & $\begin{array}{l}\text { Differential } \\
\text { diagnosis }\end{array}$ & SPEs & Not mentioned & $(38)$ \\
\hline $\begin{array}{l}\text { circRASSF2 } \\
\text { (circ_0059354) }\end{array}$ & Up & PTC vs. HC & $\begin{array}{l}\text { Differential } \\
\text { diagnosis }\end{array}$ & SPEs & Not mentioned & $(39)$ \\
\hline $\operatorname{miR}-31-5 p$ & Up & PTC vs. BG & $\begin{array}{l}\text { Differential } \\
\text { diagnosis }\end{array}$ & SPEs & Not mentioned & $(59)$ \\
\hline miR-21-5p & Up & FTC vs. BG & $\begin{array}{l}\text { Differential } \\
\text { diagnosis }\end{array}$ & SPEs & Not mentioned & $(59)$ \\
\hline $\begin{array}{l}\text { miR-346, miR-10a-5p, } \\
\text { miR-34a-5p }\end{array}$ & Up & PTC vs. HC & $\begin{array}{l}\text { Differential } \\
\text { diagnosis }\end{array}$ & SPEs & Not mentioned & $(60)$ \\
\hline $\begin{array}{l}\text { hsacirc_007293, } \\
\text { hsacirc_031752 and } \\
\text { hsacirc_020135 }\end{array}$ & Up & PTC vs. BG & $\begin{array}{l}\text { Differential } \\
\text { diagnosis }\end{array}$ & SPEs & Not mentioned & $(48)$ \\
\hline $\begin{array}{l}\operatorname{miR}-485-3 p \\
\operatorname{miR}-4433 a-5 P\end{array}$ & Up & $\begin{array}{l}\text { PTC vs. HC vs. } \\
\text { BG }\end{array}$ & $\begin{array}{l}\text { Differential } \\
\text { diagnosis, } \\
\text { Prognosis (just } \\
\text { for miR-485-3p) }\end{array}$ & SPEs & $\begin{array}{l}\text { Not mentioned with } \\
89.5 \% \text { AUCs for two } \\
\text { miRNAs used together }\end{array}$ & $(61)$ \\
\hline $\begin{array}{l}\text { miR-146b-5p, } \\
\text { miR-222-3p }\end{array}$ & Up & $\begin{array}{l}\text { PTC with vs. } \\
\text { without LNM }\end{array}$ & LNM & SPEs & $\begin{array}{l}\text { with } 89.5 \% \text { AUCs for } \\
\text { two miRNAs used } \\
\text { together }\end{array}$ & $(50)$ \\
\hline $\begin{array}{l}\operatorname{miR}-21-5 p \\
\operatorname{miR}-181 a\end{array}$ & Up & PTC vs. FTC & $\begin{array}{l}\text { Differential } \\
\text { diagnosis }\end{array}$ & SPEs & $\begin{array}{l}\text { With } 100 \% \text { sensitivity } \\
\text { and } 87 \% \text { specificity for } \\
\text { two miRNAs used } \\
\text { together }\end{array}$ & $(59)$ \\
\hline $\begin{array}{l}\operatorname{miR}-16-2-3 p \\
\operatorname{miR}-223-5 p \\
\operatorname{miR}-101-3 p, \text { and } \\
\operatorname{miR}-34 c-5 p\end{array}$ & $\begin{array}{l}\text { Only up in the } \\
\text { first two } \\
\text { miRNAs }\end{array}$ & $\begin{array}{l}\text { PTC vs. BG } \\
\text { PTC and FTC } \\
\text { before vs. after } \\
\text { the surgery }\end{array}$ & $\begin{array}{l}\text { Differential } \\
\text { diagnosis }\end{array}$ & SPEs & $\begin{array}{l}\text { with } 74 \% \text { AUCs, } 71.43 \% \\
\text { sensitivity and } 73.33 \% \\
\text { specificity for four } \\
\text { miRNAs used together }\end{array}$ & $(63)$ \\
\hline Thyroglobulin & Up & $\begin{array}{l}\text { PTC and FTC } \\
\text { before vs. after } \\
\text { the surgery }\end{array}$ & $\begin{array}{l}\text { Recurrence, } \\
\text { Prognosis }\end{array}$ & UEs & Not mentioned & (64) \\
\hline $\begin{array}{l}\text { Hsp27, Hsp60, and } \\
\text { Hsp90 }\end{array}$ & Up & $\begin{array}{l}\text { PTC vs. BG vs. } \\
\text { PT, PTC before } \\
\text { vs. after the } \\
\text { surgery }\end{array}$ & $\begin{array}{l}\text { Differential } \\
\text { diagnosis, } \\
\text { recurrence }\end{array}$ & SPEs & Not mentioned & $(65)$ \\
\hline PD-1, PD-L1 & Up & $\begin{array}{l}\text { PTC children } \\
\text { vs. HC children }\end{array}$ & $\begin{array}{l}\text { Differential } \\
\text { diagnosis }\end{array}$ & SPEs & 81.4\% AUCs for PD-L1 & $(55)$ \\
\hline
\end{tabular}

PTC, papillary thyroid carcinoma; FTC, follicular thyroid carcinoma; BG, benign goiter; HC, healthy control; PT, peritumoral tissue; LNM, lymph node metastasis; SPEs, serum purified EVs; UEs, urinary exosomes; AUC, area under the curve.

targeted and internalized into the mouse CAL62 tumor model after $30 \mathrm{~min}$ of systemic injection. The targeting characteristics of TC-derived EVs have been successfully validated, which indicates that EVs can act as an effective therapeutic agent by carrying tumor-killing factors.
The killing effect of NK cell-derived EVs on TC. As a key subpopulation of natural immune lymphocytes, natural killer (NK) cells can carry out their anti-tumor functions through cytotoxic effects. The tumor-killing ability of NK cells, coupled with the targeting ability of EVs, can expedite the progression 
of immunotherapeutic clinical applications. Zhu et al reported that the NK cell-derived-EVs, which were co-incubated with IL-15, exerted significant cell lytic and tumor growth inhibitory activity in human cancer cell lines (glioblastoma, breast cancer and TC), which was not significantly toxic to normal cells or mice (73). Furthermore, previous studies have illustrated that although the production of EVs exists in both physiological and pathological processes (74), the production of naturally secreted EVs is low (75). Therefore, to advance the clinical application of EVs, significant issues, such as EV production, need to be addressed. Incubation with IL-15 increases the NK cell production of EVs (73). Moreover, for the first time, Yang et al reported the continuous extrusion of NK cells with filters of different pore sizes (76). This method obtained exosome mimetics (EMs) with high yields and controllable size. The amount of EMs thus obtained, was higher in concentration than the purified EVs, and EMs had a better-targeted killing effect on a variety of tumor cells, including ATC. These EMs were not toxic to normal cells and tissues. Zhu et al used this method to embed siRNA into EMs through electroporation packages and verified the targeting and tumor-killing effect of NK cell-derived EMs once again (77). These methods have greatly enhanced the therapeutic prospects of anti-tumor cell-derived EVs in a variety of tumors, including TC.

\section{Conclusions and future perspectives}

Recent advances in microscopic and EV separation technology have led to an advancement in the research of EVs in TC. Their rich content and functions render EVs a complex cellular component. Differentially expressed proteins and RNAs in TC-derived EVs play a significant role in cancer progression. Over time, a plethora of potential diagnostic markers have been identified, which can facilitate the accurate diagnosis of TC in the future, reducing unnecessary thyroidectomies. TC-derived EVs can target tumor regions, and NK cell-derived EVs can inhibit thyroid progression, which opens the door to the use of EVs in TC therapy. EVs have a targeted therapeutic effect on ATC, which provides a breakthrough for its poor prognosis and limited treatment. However, quite a few issues in this field still remain unresolved. The research samples included by TC-derived EVs are generally insufficient, and more significant conclusions can be drawn by increasing the sample size and eliminating individual differences. In addition, there is still no direct evidence that EVs obtained from serum or urine are derived from TC cells, which remains a challenging question in exosomal research. Concisely, in-depth research investigations are required to unravel the unexplored areas of EV research, which may also unravel the precise mechanisms for the EV-mediated onset and progression of TC along with the clinical diagnosis and treatment.

\section{Acknowledgements}

Not applicable.

\section{Funding}

The present study was supported by the Science Foundation of Gansu Province (no. 18JR3RA343) and Science and
Technology Bureau 2018 Fund of the Chengguan District (no. 2018KJGG0037).

\section{Availability of data and materials}

Not applicable.

\section{Authors' contributions}

YL, YZ and WY were involved in the conception of the study subject. NL, XN and SP were involved in the study design and the acquisition of data for the purposes of the present review. YL, NL and WY were involved in the writing of the article and in revising the manuscript. All authors have read and approved the final manuscript.

\section{Ethics approval and consent to participate}

Not applicable.

\section{Patient consent for publication}

Not applicable.

\section{Competing interests}

The authors declare that they have no competing interests.

\section{References}

1. Siegel RL, Miller KD and Jemal A: Cancer statistics, 2020. CA Cancer J Clin 70: 7-30, 2020.

2. Yang L, Zheng RS, Wang N, Zeng HM, Yuan YN, Zhang SW, $\mathrm{Li} \mathrm{HC}$, Liu S, Chen WQ and He J: Analysis of incidence and mortality of thyroid cancer in China, 2013. Zhonghua Zhong Liu Za Zhi 39: 862-867, 2017 (In Chinese).

3. Cronin KA, Lake AJ, Scott S, Sherman RL, Noone AM, Howlader N, Henley SJ, Anderson RN, Firth AU, Ma J, et al: Annual report to the nation on the status of cancer, part I: National cancer statistics. Cancer 124: 2785-2800, 2018.

4. Yassa L, Cibas ES, Benson CB, Frates MC, Doubilet PM, Gawande AA, Moore FD Jr, Kim BW, Nose V, Marqusee E, et al: Long-term assessment of a multidisciplinary approach to thyroid nodule diagnostic evaluation. Cancer 111: 508-516, 2007.

5. Cooper DS, Doherty GM, Haugen BR, Kloos RT, Lee SL, Mandel SJ, Mazzaferri EL, McIver B, Pacini F, Schlumberger M, et al: Revised American Thyroid Association management guidelines for patients with thyroid nodules and differentiated thyroid cancer. Thyroid 19: 1167-1214, 2009.

6. Sahin M, Gursoy A, Tutuncu NB and Guvener DN: Prevalence and prediction of malignancy in cytologically indeterminate thyroid nodules. Clin Endocrinol (Oxf) 65: 514-518, 2006.

7. Gomez Saez JM: Diagnostic and prognostic markers in differentiated thyroid cancer. Curr Genomics 12: 597-608, 2011.

8. Jegerlehner S, Bulliard JL, Aujesky D, Rodondi N, Germann S, Konzelmann I and Chiolero A: Overdiagnosis and overtreatment of thyroid cancer: A population-based temporal trend study. PLoS One 12: e0179387, 2017.

9. Miller KD, Nogueira L, Mariotto AB, Rowland JH, Yabroff KR, Alfano CM, Jemal A, Kramer JL and Siegel RL: Cancer treatment and survivorship statistics, 2019. CA Cancer J Clin 69: 363-385, 2019.

10. Tkach $\mathrm{M}$ and Thery $\mathrm{C}$ : Communication by extracellular vesicles: Where we are and where we need to go. Cell 164: 1226-1232, 2016.

11. Raposo G and Stoorvogel W: Extracellular vesicles: Exosomes, microvesicles, and friends. J Cell Biol 200: 373-383, 2013.

12. Maas SLN, Breakefield XO and Weaver AM: Extracellular vesicles: Unique intercellular delivery vehicles. Trends Cell Biol 27: 172-188, 2017. 
13. Gallo A, Tandon M, Alevizos I and Illei GG: The majority of microRNAs detectable in serum and saliva is concentrated in exosomes. PLoS One 7: e30679, 2012.

14. Ren J, He W, Zheng L and Duan H: From structures to functions: Insights into exosomes as promising drug delivery vehicles. Biomater Sci 4: 910-921, 2016.

15. EL Andaloussi S, Mäger I, Breakefield XO and Wood MJ: Extracellular vesicles: Biology and emerging therapeutic opportunities. Nat Rev Drug Discov 12: 347-357, 2013.

16. Gilligan KE and Dwyer RM: Engineering exosomes for cancer therapy. Int J Mol Sci 18: 1122, 2017.

17. Namee NM and O'Driscoll L: Extracellular vesicles and anti-cancer drug resistance. Biochim Biophys Acta Rev Cancer 1870: 123-136, 2018.

18. Mori MA, Ludwig RG, Garcia-Martin R, Brandão BB and Kahn CR: Extracellular miRNAs: From biomarkers to mediators of physiology and disease. Cell Metab 30: 656-673, 2019.

19. Suchorska WM and Lach MS: The role of exosomes in tumor progression and metastasis (Review). Oncol Rep 35: 1237-1244, 2016.

20. Margolis L and Sadovsky Y: The biology of extracellular vesicles: The known unknowns. PLoS Biol 17: e3000363, 2019.

21. Vella LJ, Hill AF and Cheng L: Focus on extracellular vesicles: Exosomes and their role in protein trafficking and biomarker potential in alzheimer's and parkinson's disease. Int J Mol Sci 17: 173,2016

22. Zhang Y, Xi H, Nie X, Yuan W, Zhang P, Lan N, Lu Y, Liu J and Yuan W: Assessment of miR-212 and other biomarkers in the diagnosis and treatment of HBV-infection-related liver diseases. Curr Drug Metab 20: 785-798, 2019.

23. Colombo M, Raposo G and Thery C: Biogenesis, secretion, and intercellular interactions of exosomes and other extracellular vesicles. Annu Rev Cell Dev Biol 30: 255-289, 2014.

24. Pegtel DM and Gould SJ. Exosomes. Annu Rev Biochem 88 487-514, 2019.

25. Théry C, Witwer KW, Aikawa E, Alcaraz MJ, Anderson JD, Andriantsitohaina R, Antoniou A, Arab T, Archer F, Atkin-Smith GK, et al: Minimal information for studies of extracellular vesicles 2018 (MISEV2018): A position statement of the International Society for Extracellular Vesicles and update of the MISEV2014 guidelines. J Extracell Vesicles 7: 1535750, 2018.

26. Trams EG, Lauter CJ, Salem N Jr and Heine U: Exfoliation of membrane ecto-enzymes in the form of micro-vesicles. Biochim Biophys Acta 645: 63-70, 1981.

27. Harding C, Heuser J and Stahl P: Endocytosis and intracellular processing of transferrin and colloidal gold-transferrin in rat reticulocytes: Demonstration of a pathway for receptor shedding. Eur J Cell Biol 35: 256-263, 1984.

28. Johnstone RM, Adam M, Hammond JR, Orr L and Turbide C: Vesicle formation during reticulocyte maturation. Association of plasma membrane activities with released vesicles (exosomes) J Biol Chem 262: 9412-9420, 1987.

29. Raposo G, Nijman HW, Stoorvogel W, Liejendekker R, Harding CV, Melief CJ and Geuze HJ: B lymphocytes secrete antigen-presenting vesicles. J Exp Med 183: 1161-1172, 1996.

30. Zitvogel L, Regnault A, Lozier A, Wolfers J, Flament C, Tenza D, Ricciardi-Castagnoli P, Raposo G and Amigorena S: Eradication of established murine tumors using a novel cell-free vaccine: Dendritic cell-derived exosomes. Nat Med 4: 594-600, 1998.

31. Valadi H, Ekström K, Bossios A, Sjöstrand M, Lee JJ and Lötvall JO: Exosome-mediated transfer of mRNAs and microRNAs is a novel mechanism of genetic exchange between cells. Nat Cell Biol 9: 654-659, 2007.

32. Vanaja SK, Russo AJ, Behl B, Banerjee I, Yankova M, Deshmukh SD and Rathinam VAK: Bacterial outer membrane vesicles mediate cytosolic localization of LPS and caspase-11 activation. Cell 165: 1106-1119, 2016.

33. Mizrak A, Bolukbasi MF, Ozdener GB, Brenner GJ, Madlener S, Erkan EP, Ströbel T, Breakefield XO and Saydam O: Genetically engineered microvesicles carrying suicide mRNA/protein inhibit schwannoma tumor growth. Mol Ther 21: 101-108, 2013.

34. Maacha S, Bhat AA, Jimenez L, Raza A, Haris M, Uddin S and Grivel JC: Extracellular vesicles-mediated intercellular communication: Roles in the tumor microenvironment and anti-cancer drug resistance. Mol Cancer 18: 55, 2019.

35. Lee JC, Zhao JT, Gundara J, Serpell J, Bach LA and Sidhu S: Papillary thyroid cancer-derived exosomes contain miRNA-146b and miRNA-222. J Surg Res 196: 39-48, 2015.

36. Geraldo MV, Yamashita AS and Kimura ET: MicroRNA miR-146b-5p regulates signal transduction of TGF- $\beta$ by repressing SMAD4 in thyroid cancer. Oncogene 31: 1910-1922, 2012.
37. Visone R, Russo L, Pallante P, De Martino I, Ferraro A, Leone V, Borbone E, Petrocca F, Alder H, Croce CM and Fusco A: MicroRNAs (miR)-221 and miR-222, both overexpressed in human thyroid papillary carcinomas, regulate p27Kip1 protein levels and cell cycle. Endocr Relat Cancer 14: 791-798, 2007.

38. Wu G, Zhou W, Pan X, Sun Z, Sun Y, Xu H, Shi P, Li J, Gao L and Tian X: Circular RNA profiling reveals exosomal circ_0006156 as a novel biomarker in papillary thyroid cancer. Mol Ther Nucleic Acids 19: 1134-1344, 2020.

39. Wu G, Zhou W, Lin X, Sun Y, Li J, Xu H, Shi P, Gao L and Tian X: circRASSF2 Acts as ceRNA and promotes papillary thyroid carcinoma progression through miR-1178/TLR4 signaling pathway. Mol Ther Nucleic Acids 19: 1153-1163, 2020.

40. Greening DW, Gopal SK, Mathias RA, Liu L, Sheng J, Zhu HJ and Simpson RJ: Emerging roles of exosomes during epithelial-mesenchymal transition and cancer progression. Semin Cell Dev Biol 40: 60-71, 2015.

41. Luo D, Zhan S, Xia W, Huang L, Ge W and Wang T: Proteomics study of serum exosomes from papillary thyroid cancer patients. Endocr Relat Cancer 25: 879-891, 2018.

42. Peinado H, Alečković M, Lavotshkin S, Matei I, Costa-Silva B, Moreno-Bueno G, Hergueta-Redondo M, Williams C, García-Santos G, Ghajar C, et al: Melanoma exosomes educate bone marrow progenitor cells toward a pro-metastatic phenotype through MET. Nat Med 18: 883-891, 2012.

43. Melo SA, Luecke LB, Kahlert C, Fernandez AF, Gammon ST, Kaye J, LeBleu VS, Mittendorf EA, Weitz J, Rahbari N, et al: Glypican-1 identifies cancer exosomes and detects early pancreatic cancer. Nature 523: 177-182, 2015

44. Costa-Silva B, Aiello NM, Ocean AJ, Singh S, Zhang H, Thakur BK, Becker A, Hoshino A, Mark MT, Molina H, et al: Pancreatic cancer exosomes initiate pre-metastatic niche formation in the liver. Nat Cell Biol 17: 816-826, 2015.

45. Henderson YC, Toro-Serra R, Chen Y, Ryu J, Frederick MJ, Zhou G, Gallick GE, Lai SY and Clayman GL: Src inhibitors in suppression of papillary thyroid carcinoma growth. Head Neck 36: 375-384, 2014

46. Wang C, Yan G, Zhang Y, Jia X and Bu P: Long non-coding RNA MEG3 suppresses migration and invasion of thyroid carcinoma by targeting of Rac1. Neoplasma 62: 541-549,2015

47. Hardin H, Helein H, Meyer K, Robertson S, Zhang R, Zhong W and Lloyd R V: Thyroid cancer stem-like cell exosomes: Regulation of EMT via transfer of IncRNAs. Lab Invest 98: 1133-1142, 2018.

48. Yang C, Wei Y, Yu L and Xiao Y: Identification of altered circular RNA expression in serum exosomes from patients with papillary thyroid carcinoma by high-throughput sequencing. Med Sci Moni 25: 2785-2791, 2019.

49. Ye W, Deng X and Fan Y: Exosomal miRNA423-5p mediated oncogene activity in papillary thyroid carcinoma: A potential diagnostic and biological target for cancer therapy. Neoplasma 66 : 516-523, 2019.

50. Jiang K, Li G, Chen W, Song L, Wei T, Li Z, Gong R, Lei J, Shi H and Zhu J: Plasma Exosomal miR-146b-5p and miR-222-3p are potential biomarkers for lymph node metastasis in papillary thyroid carcinomas. Onco Targets Ther 13: 1311-1319, 2020.

51. Thery C, Zitvogel L and Amigorena S. Exosomes: Composition, biogenesis and function. Nat Rev Immunol 2: 569-579, 2002.

52. Bravo-Miana RDC, Della Vedova AB, De Paul AL, Remedi MM, Guantay ML, Gilardoni MB, Pellizas CG and Donadio AC: Thyroid tumor cells-fibroblasts crosstalk: Role of extracellular vesicles. Endocr Connect 9: 506-518, 2020

53. Wu F, Li F, Lin X, Xu F, Cui RR, Zhong JY, Zhu T, Shan SK, Liao XB, Yuan LQ and Mo ZH: Exosomes increased angiogenesis in papillary thyroid cancer microenvironment. Endocr Relat Cancer 26: 525-538, 2019

54. van Niel G, D'Angelo G and Raposo G: Shedding light on the cell biology of extracellular vesicles. Nat Rev Mol Cell Biol 19: 213-228, 2018.

55. Wang G, Wang S, Zhang M, Li Y, Liu Q, Sun N, Zhang X, Liu Y, Zhang J,He L, et al: EV PD-L1 is correlated with clinical features and contributes to $t$ cell suppression in pediatric thyroid cancer. J Clin Endocrinol Metab 105: dgaa309, 2020.

56. Cheng L, Sharples RA, Scicluna BJ and Hill AF: Exosomes provide a protective and enriched source of miRNA for biomarker profiling compared to intracellular and cell-free blood. J Extracell Vesicles 3, 2014

57. Qiao F, Pan P, Yan J, Sun J, Zong Y, Wu Z, Lu X, Chen N, Mi R, Ma Y and Ji Y: Role of tumor-derived extracellular vesicles in cancer progression and their clinical applications (Review). Int J Oncol 54: 1525-1533, 2019 
58. Pan Q,Zhao J,Li M, Liu X, Xu Y, Li W, Wu S and Su Z: Exosomal miRNAs are potential diagnostic biomarkers between malignant and benign thyroid nodules based on next-generation sequencing. Carcinogenesis 41: 18-24, 2020.

59. Samsonov R, Burdakov V, Shtam T, Radzhabovsmall Z, Vasilyev D, Tsyrlina E, Titov S, Ivanov M, Berstein L, et al: Plasma exosomal miR-21 and miR-181a differentiates follicular from papillary thyroid cancer. Tumour Biol 37: 12011-12021, 2016.

60. Wang Z, Lv J, Zou X, Huang Z, Zhang H, Liu Q, Jiang L, Zhou X and Zhu W: A three plasma microRNA signature for papillary thyroid carcinoma diagnosis in Chinese patients. Gene 693: 37-45, 2019.

61. Dai D, Tan Y, Guo L, Tang A and Zhao Y: Identification of exosomal miRNA biomarkers for diagnosis of papillary thyroid cancer by small RNA sequencing. Eur J Endocrinol 182: 111-121, 2020.

62. Rappa G, Puglisi C, Santos MF, Forte S, Memeo L and Lorico A: Extracellular vesicles from thyroid carcinoma: The new frontier of liquid biopsy. Int J Mol Sci 20: 1114, 2019.

63. Liang M, Yu S, Tang S, Bai L, Cheng J, Gu Y, Li S, Zheng X, Duan L, Wang L, et al: A Panel of Plasma exosomal miRNAs as potential biomarkers for differential diagnosis of thyroid nodules. Front Genet 11: 449, 2020.

64. Huang TY, Wang CY, Chen KY and Huang LT: Urinary exosomal thyroglobulin in thyroid cancer patients with post-ablative therapy: A new biomarker in thyroid cancer. Front Endocrinol (Lausanne) 11: 382, 2020.

65. Caruso Bavisotto C, Cipolla C, Graceffa G, Barone R, Bucchieri F, Bulone D, Cabibi D, Campanella C, Marino Gammazza A, Pitruzzella A, et al: Immunomorphological pattern of molecular chaperones in normal and pathological thyroid tissues and circulating exosomes: Potential use in Clinics. Int J Mol Sci 20: 4496 2019 .

66. Zhuang X, Xiang X, Grizzle W, Sun D, Zhang S, Axtell RC Ju S, Mu J, Zhang L, Steinman L, et al: Treatment of brain inflammatory diseases by delivering exosome encapsulated anti-inflammatory drugs from the nasal region to the brain. Mol Ther 19: 1769-1779, 2011.

67. Yang T, Martin P, Fogarty B, Brown A, Schurman K, Phipps R, Yin VP, Lockman P and Bai S: Exosome delivered anticancer drugs across the blood-brain barrier for brain cancer therapy in Danio rerio. Pharm Res 32: 2003-2014, 2015.
68. Smyth T, Kullberg M, Malik N, Smith-Jones P, Graner MW and Anchordoquy TJ: Biodistribution and delivery efficiency of unmodified tumor-derived exosomes. J Control Release 199: 145-155, 2015.

69. Kim SM, Yang Y, Oh SJ, Hong Y, Seo M and Jang M: Cancer-derived exosomes as a delivery platform of CRISPR/Cas9 confer cancer cell tropism-dependent targeting. J Control Release 266: 8-16, 2017.

70. Rana S, Yue S, Stadel D and Zöller M: Toward tailored exosomes: The exosomal tetraspanin web contributes to target cell selection. Int J Biochem Cell Biol 44: 1574-1584, 2012.

71. Zhang H, Wang Y, Bai M, Wang J, Zhu K, Liu R, Ge S, Li J, Ning T, Deng T, et al: Exosomes serve as nanoparticles to suppress tumor growth and angiogenesis in gastric cancer by delivering hepatocyte growth factor siRNA. Cancer Sci 109: 629-641, 2018.

72. Gangadaran P, Li XJ, Kalimuthu SK, Min OJ, Hong CM, Rajendran RL, Lee HW, Zhu L, Baek SH and Jeong SY: New optical imaging reporter-labeled anaplastic thyroid cancer-derived extracellular vesicles as a platform for in vivo tumor targeting in a mouse model. Sci Rep 8: 13509, 2018.

73. Zhu L, Kalimuthu S, Oh JM, Gangadaran P, Baek SH, Jeong SY, Lee SW, Lee J and Ahn BC: Enhancement of antitumor potency of extracellular vesicles derived from natural killer cells by IL-15 priming. Biomaterials 190-191: 38-50, 2019

74. Lugini L, Cecchetti S, Huber V, Luciani F, Macchia G, Spadaro F, Paris L, Abalsamo L, Colone M, Molinari A, et al: Immune surveillance properties of human NK cell-derived exosomes. J Immunol 189: 2833-2842, 2012.

75. Kim OY, Choi SJ, Jang SC, Park KS, Kim SR, Choi JP, Lim JH, Lee SW, Park J, Di Vizio D, et al: Bacterial protoplast-derived nanovesicles as vaccine delivery system against bacterial infection. Nano Lett 15: 266-274, 2015.

76. Yang Z, Xie J, Zhu J, Kang C, Chiang C, Wang X, Wang X, Kuang T, Chen F, Chen Z, et al: Functional exosome-mimic for delivery of siRNA to cancer: In vitro and in vivo evaluation. J Control Release 243: 160-171, 2016.

77. Zhu L, Gangadaran P, Kalimuthu S, Oh JM, Baek SH, Jeong SY, Lee SW, Lee J and Ahn BC: Novel alternatives to extracellular vesicle-based immunotherapy-exosome mimetics derived from natural killer cells. Artif Cells Nanomed Biotechnol 46 (sup3): S166-S179, 2018. 